\title{
A prática de análise linguística na BNCC e a perspectiva sociocultural de ensino e aprendizagem: (in)congruências teórico-metodológicas
}

\author{
Francieli Matzenbacher Pinton ${ }^{1}$ \\ Romário Volk ${ }^{2}$ \\ Rosana Maria Schmitt ${ }^{3}$ \\ Programa de Pós-Graduação em Letras, Universidade Federal de Santa Maria, Santa Maria, RS, Brasil
}

Resumo: Considerando que a Base Nacional Comum Curricular é um documento de caráter normativo e objetiva determinar as práticas pedagógicas desenvolvidas nas três etapas da educação básica, focalizamos, neste artigo, a área de Linguagens, em específico a disciplina Língua Portuguesa, a fim de analisar em que medida o eixo de Análise Linguística/Semiótica, anos finais (6 a 9 o ano - Todos os Campos de Atuação), apresentado na BNCC, alinha-se à perspectiva sociocultural de ensino e aprendizagem, promovendo uma formação crítico-reflexiva. Os resultados apontam uma dicotomia, no eixo de Análise Linguística/Semiótica (Todos os campos de atuação), em relação ao que deve ser feito "para" o aluno e "como" isso deve ser feito: enquanto uma perspectiva sociocultural assume que, para que o aluno desenvolva a autonomia linguística, é imprescindível construir andaimes de aprendizagem, a BNCC, assumindo esse mesmo objetivo, não apresenta uma estrutura de habilidades para o ensino de Língua Portuguesa que possibilite essa construção.

Palavras-chave: BNCC; Prática de Análise Linguística; Teoria Sociocultural.

Title: The Practice of Linguistical Analysis in the BNCC and the Sociocultural Perspective of Teaching and Learning: theoretical-methodological (in)congruences.

Abstract: Considering that the Common National Curricular Base (BNCC) is a document of normative character and seeks to determine the pedagogical practices developed in the three steps of basic education, we focused, on this article, the area of Language, specifically the discipline of Portuguese, with the intent of analyzing to what extent the axis of Linguistical/Semiotic Analysis (All fields of action), presented in the BNCC, aligns with the sociocultural perspective of teaching and learning, promoting the development of critical thinking and reflection. The results point to a dichotomy, in the axis of

\footnotetext{
${ }^{1}$ Doutora em Estudos Linguísticos pelo Programa de Pós-Graduação em Letras (PPGL/UFSM), Professora do Departamento de Letras Vernáculas (graduação em Letras) e do Programa de Pós-Graduação em Letras da Universidade Federal de Santa Maria (PPGL/UFSM). Orcid: https://orcid.org/0000-0001-6821-4927.

E-mail: francieli.matzembacher@gmail.com

${ }^{2}$ Mestrando em Estudos Linguísticos pelo Programa de Pós-Graduação em Letras da Universidade Federal de Santa Maria (PPGL/UFSM). Orcid: https://orcid.org/0000-0002-0374-9987

E-mail: romariovolk92@gmail.com

${ }^{3}$ Mestranda em Estudos Linguísticos pelo Programa de Pós-Graduação em Letras da Universidade Federal de Santa Maria (PPGL/UFSM). Orcid: https://orcid.org/0000-0001-6387-1418

E-mail: rosanaschmitt30@gmail.com
} 
Linguistical/Semiotic analysis (All fields of action), regarding what should be done "for" the student and "how" this should be done: while a sociocultural perspective assumes that, for the student to develop linguistic autonomy, it's necessary to build learning scaffolds, the BNCC, having this same objective, does not present an ability structure for teaching the Portuguese Language that allow this construction.

Keywords: BNCC; Practice of Linguistical Analysis; Sociocultural Theory.

\section{Introdução}

A Base Nacional Comum Curricular (BNCC) é um documento de caráter normativo, fundamentado em consonância com marcos legais elementares na história da educação (Constituição Federal, Lei de Diretrizes e Bases, Diretrizes Curriculares Nacionais, Plano Nacional da Educação), que objetiva determinar as práticas pedagógicas desenvolvidas nas três etapas da educação básica a fim de superar antigos problemas de qualidade e equidade. Elaborada a partir de dez competências gerais que nortearão o trabalho dos professores e das escolas públicas e privadas do país, a BNCC apresenta competências e habilidades específicas para cada área do conhecimento e componentes curriculares.

$\mathrm{Na}$ área de Linguagens, especificamente na etapa Ensino Fundamental, a BNCC objetiva proporcionar aos estudantes "experiências que contribuam para a ampliação dos letramentos, de forma a possibilitar a participação significativa e crítica nas diversas práticas sociais permeadas/constituídas pela oralidade, pela escrita e por outras linguagens" (BRASIL, 2018, p. 67-68). A fim de promover o protagonismo dos alunos frente às diversas práticas sociais permeadas pela linguagem, as aprendizagens propostas para o ensino de Língua Portuguesa são organizadas em quatro eixos de ensino (Leitura/Escuta, Produção de Textos, Oralidade e Análise Linguística/Semiótica). Desse modo, entendemos que tomar o eixo da Análise Linguística/Semiótica como ponto de partida é pertinente para a compreensão, em sentido mais amplo, das concepções de ensino e aprendizagem que o documento revela, pois enquanto eixo, como a própria designação sugere, a Análise Linguística/Semiótica articula, simultaneamente, atividades de leitura e produção textual. Assim, objetivamos analisar em que medida o eixo de Análise Linguística/Semiótica, anos finais (6으, 7으, 8o e 9은 ano) do Ensino Fundamental, apresentado na BNCC, alinha-se à perspectiva sociocultural de ensino e aprendizagem, ou seja, em que medida propõe uma reflexão mediada pela linguagem, pela adoção de andaimes de aprendizagem e pelo desenvolvimento da autonomia (por meio da construção de conceitos verdadeiros). Para isso, tomamos por base a Prática de Análise Linguística (PAL), abordagem de ensino de gramática caracterizada por um viés crítico-reflexivo, que se pauta em uma abordagem sociocultural de ensino e aprendizagem.

Além desta seção de Introdução, o texto está organizado da seguinte maneira: na 
segunda seção, revisamos a Teoria sociocultural e a abordagem de Prática de Análise Linguística; na terceira seção, apresentamos o universo de análise, corpus e procedimentos; na quarta seção, expomos e discutimos a análise contextual e textual; e, por fim, na quinta e sexta seções, apresentamos as considerações finais e listamos as referências bibliográficas que orientaram este estudo.

\section{Referencial Teórico}

A seguir, apresentamos considerações breves sobre a teoria sociocultural de ensino e aprendizagem e a abordagem de Prática de Análise Linguística. Essa proposta de ensino de gramática norteará nossa análise do corpus selecionado, uma vez que se alinha à perspectiva de ensino e aprendizagem que entendemos como sendo a mais adequada para a orientação das práticas pedagógicas do professor frente ao ensino de Língua Portuguesa.

\section{Teoria Sociocultural}

A teoria sociocultural, postulada por Lev Vygotsky (1896-1934), propõe que a distinção entre pessoas e animais é estabelecida pela cultura. O termo cultura, em sua acepção, é compreendido como produto da vida social e da atividade social do homem. Nesse sentido, "a cultura é o resultado de tudo aquilo que o homem produz utilizando-se de instrumento no contexto social". (FARIAS; BORTOLANZA, 2013).

Para Vygotsky o processo de aprendizagem no indivíduo ocorre mediado pelo signo linguístico, o qual é responsável pela orientação e o domínio dos processos psíquicos (FRIEDRICH, 2012). É a palavra, segundo o teórico, que permite pensar o mundo, para além de representá-lo. E sendo o signo, por sua vez, exterior (e, portanto, socialmente constituído), ensino e aprendizagem são processos sociais por natureza.

No campo pedagógico e, especialmente no ensino de linguagem, o legado de Vygotsky mostra-se extremamente profícuo, sobretudo pela exploração dos conceitos de Zona de Desenvolvimento Proximal (ZDP), a relação entre conceitos verdadeiros versus pseudoconceitos e a compreensão do processo de ensino e aprendizagem enquanto prática mediada. A ZDP antecipa os desenvolvimentos possíveis, o que a criança (ou aluno) poderá fazer se acompanhada de pares mais experientes (o professor, por exemplo), na resolução de tarefas e problemas; é, nas palavras do autor: 
a distância entre o nível real (da criança) de desenvolvimento determinado pela resolução de problemas independentemente e o nível de desenvolvimento potencial determinado pela resolução de problemas sob orientação de adultos ou com colaboração de adultos mais capacitados. (VYGOTSKY, 1991, p. 83).

O conceito de ZDP atrela-se ao conceito de mediação a que já nos referimos, uma vez que é provavelmente o adulto (no caso da criança que ainda não frequenta a escola, e o professor, no caso do aluno), que pode mediar os avanços, por parte dos indivíduos "menos experientes", em direção a conceitos cada vez mais complexos (muito embora a socialização da criança ou do aluno com seus pares também proporcione avanços e desenvolvimento). Trata-se, aqui, de saber o diferente, "aquilo que eu ainda não sei", mas que outrem sabe e pode "me levar a saber também". Em sentido mais amplo, a mediação é, portanto, "a intervenção de um elemento intermediário em uma relação que o homem tem com o objeto, com outros seres humanos e consigo mesmo, esse elemento pode ser uma ferramenta, um signo ou outros seres humanos". (FIGUEIREDO, 2019).

A noção vygotskyana de conceitos verdadeiros $x$ pseudoconceitos também é imprescindível para um processo de ensino e aprendizagem que se proponha a ser eficaz. Essa noção está associada à noção de conceitos cotidianos (aqueles que a criança aprende fora da escola, no contato diário com o mundo, com as pessoas ao seu redor) e de conceitos científicos (aqueles cuja abordagem é a especificidade da escola, pois se dão sempre por intermédio de outro conceito). Conceitos verdadeiros, então, são aqueles que se "baseiam na capacidade que o homem tem de tomar as coisas fora das relações nas quais elas se deram na experiência, além de seus traços empíricos atestáveis" (FRIEDRICH, 2012, p. 94).

Muitas vezes, entretanto, ocorre que a escola não medeia de maneira satisfatória, justamente porque essa capacidade não é desenvolvida no aluno, o qual não consegue atingir autonomia frente ao conceito, por exemplo, do que seja um verbo, porque não consegue compreender o papel dessa categoria em um texto; "até o emprega corretamente em uma situação concreta, mas quando tenta defini-lo verbalmente, seu pensamento se choca [...] há extrema dificuldade e a definição que faz dele é inadequada" (FRIEDRICH, 2012, p, 98). Nesse caso, podemos entender que o aluno não ultrapassou o nível de um pseudoconceito, pois "os conceitos não são produtos da reflexão lógica do adolescente, mas aparecem nele por outro caminho, e só se tornam conscientes e lógicos muito mais tarde" (FRIEDRICH, 2012, p. 98). Acrescentamos ainda que às vezes não se tornam lógicos e conscientes nunca, jamais atingindo o nível de um conceito verdadeiro.

Cabe à escola, portanto, construir "andaimes" para que o aluno passe a compreender e apropriar-se de conceitos gradativamente mais complexos: da primeira para a segunda ordem; daquilo que o aluno já conhece em direção àquilo que ele ainda precisa conhecer; daquilo que ele já domina para aquilo que, em uma perspectiva de ZDP, pode vir a dominar em dado momento de sua aprendizagem. O conceito de andaime refere-se, dessa forma, à 
orientação que os professores proporcionam aos estudantes "para que se desenvolvam em seu processo de aprendizagem" (FIGUEIREDO, 2019). Ainda que Vygotsky não tenha empregado o termo, outros autores estabeleceram a relação entre o termo andaime e ZDP.

Diante disso, entendemos que as atividades realizadas em sala de aula, as orientações, habilidades e competências preconizadas pelos documentos e currículos escolares, para se inserirem em uma perspectiva sociocultural, devem contemplar a noção de andaimes, os quais precisam ser construídos pelo professor e também na interação entre alunos para, em última instância, promover a autonomia linguística do aluno.

Desse modo, para compreender em que medida o corpus selecionado contempla essas noções, ancoramo-nos, principalmente, na perspectiva de Prática de Análise Linguística (PAL), uma vez que, de nosso ponto de vista, ela está alinhada aos pressupostos teóricos defendidos por Vygotsky. Além disso, eleger esse procedimento investigativo justifica-se pelo fato de que as habilidades analisadas pertencem ao eixo de Análise Linguística/Semiótica. Essa relação está representada na Figura 1 a seguir:

Figura 1 - Relação teoria sociocultural de ensino e aprendizagem $x$ abordagem de PAL $x$ práticas pedagógicas para o ensino de Língua Portuguesa

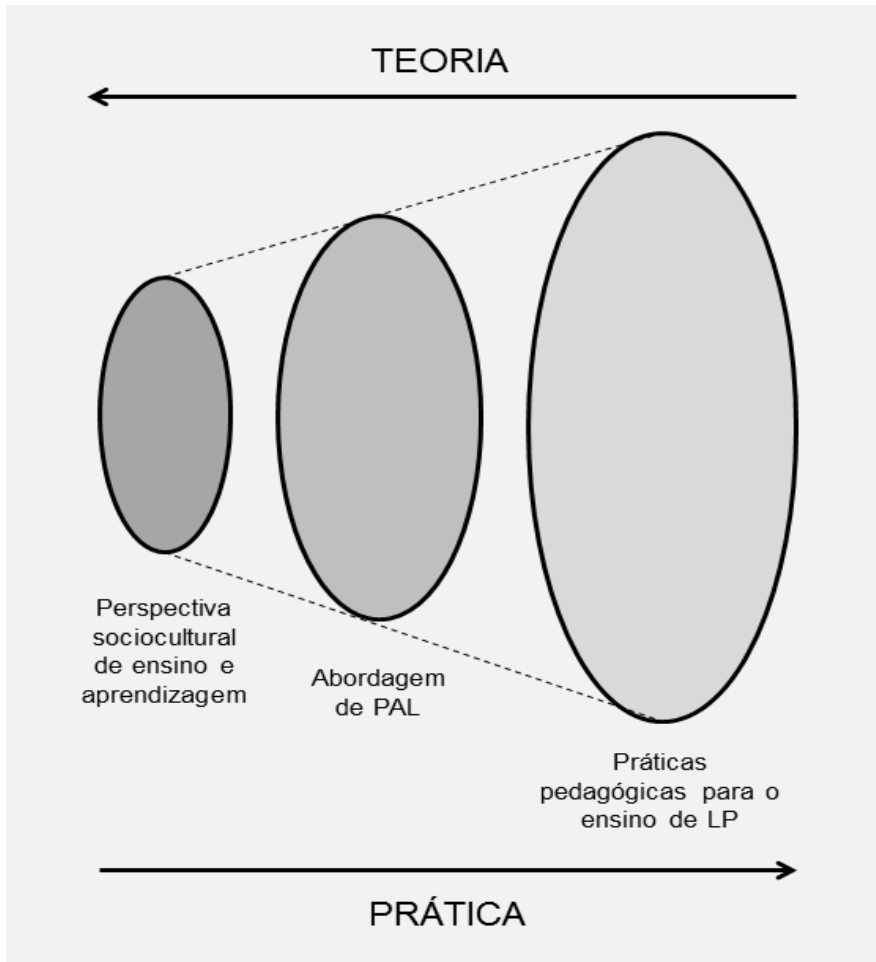

Fonte: Elaborada pelos autores (2020).

Dos pressupostos teóricos da teoria sociocultural de ensino e aprendizagem, a "perspectiva de andaimes" assume papel fundamental, pois permite a adoção de práticas situadas que auxiliem o aluno no seu percurso de aprendizagem que vai do "conhecido ao 
desconhecido" por meio de níveis conceituais gradativamente mais complexos. Neste estudo, adotamos, em relação a esse quesito, um movimento analítico que considera "os objetivos educacionais relacionados às operações mentais necessárias para alcançar determinados objetivos" (LINO DE ARAÚJO, 2017, p. 29), propostos na Taxonomia dos objetivos educacionais do domínio cognitivo, elaborada por Bloom et al. (1983).

Quadro 1 - Objetivos educacionais por níveis de complexidade

\begin{tabular}{|c|c|c|}
\hline $\begin{array}{c}\text { Níveis de } \\
\text { complexidade }\end{array}$ & Domínios & Verbos relacionados \\
\hline \multirow{2}{*}{ Básico } & $\begin{array}{l}\text { (RE)CONHECIMENTO: capacidade de identificação das } \\
\text { propriedades fundamentais dos objetos de } \\
\text { conhecimento apreendidos. }\end{array}$ & $\begin{array}{l}\text { Identificar, nomear, } \\
\text { assinalar, citar, relacionar, } \\
\text { completar, observar. }\end{array}$ \\
\hline & $\begin{array}{l}\text { COMPREENSÃO: indicação de elementos que dão } \\
\text { significado ao objeto de conhecimento, sua } \\
\text { composição, finalidade, características etc. }\end{array}$ & $\begin{array}{l}\text { Explicar, descrever, } \\
\text { caracterizar. }\end{array}$ \\
\hline \multirow{3}{*}{ Intermediário } & $\begin{array}{l}\text { APLICAÇÃO: transposição da compreensão de um } \\
\text { objeto de conhecimento em caso específico, situação- } \\
\text { problema etc. }\end{array}$ & $\begin{array}{l}\text { Resolver, aplicar (com } \\
\text { base no texto), } \\
\text { transformar, explicar. }\end{array}$ \\
\hline & $\begin{array}{l}\text { ANÁLISE: percepção da inter-relação entre o todo e } \\
\text { suas partes. }\end{array}$ & $\begin{array}{l}\text { Analisar, examinar, } \\
\text { decompor (sentença), } \\
\text { escandir. }\end{array}$ \\
\hline & SÍNTESE: reorganização das partes de um todo. & Resumir, generalizar. \\
\hline Avançado & $\begin{array}{l}\text { AVALIAÇÃO: emissão de juízo de valor sobre análises e } \\
\text { sínteses efetuadas. }\end{array}$ & $\begin{array}{l}\text { Julgar, justificar, } \\
\text { apresentar argumentos. }\end{array}$ \\
\hline
\end{tabular}

Fonte: Lino de Araújo (2017, p. 29-30).

\section{Abordagem de Prática de Análise Linguística}

A Prática de Análise Linguística (PAL) para fins didáticos é um termo cunhado por Geraldi, nas obras O texto na sala de aula (1984) e Portos de Passagem (1997), para se referir ao "conjunto de atividades que tomam uma das características da linguagem como seu objeto: o fato de ela poder remeter a si própria" (GERALDI, 1997, p. 189). Nesse viés, essa designação corresponde a um modelo teórico-metodológico ${ }^{4}$ que prestigia atividades que têm como objetivo central refletir sobre elementos e fenômenos linguísticos da língua portuguesa e sobre estratégias discursivas, com foco nos usos da linguagem (BEZERRA; REINALDO, 2013). Nesse sentido, a PAL promove, a respeito da língua, "uma reflexão

\footnotetext{
${ }^{4}$ É teórico porque constitui um conceito que remete a uma forma de observação de dados de uma língua, apoiada em uma teoria; é metodológico porque é utilizado na sala de aula como um recurso para o ensino reflexivo da língua (BEZERRA; REINALDO, 2013).
} 
recorrente e organizada, voltada para a produção de sentidos e/ou para a compreensão mais ampla dos usos e do sistema linguístico" (BEZERRA; REINALDO, 2013, p. 208). Dessa maneira, preconiza-se que os alunos sejam capazes de, no final do período escolar, lerem e/ou escreverem, com autonomia e eficiência, diversos gêneros textuais, instanciados pelas mais variadas práticas sociocomunicativas.

Para que tal prática se efetive de maneira satisfatória, a escola precisa que sejam abandonadas antigas abordagens de ensino gramatical, e que estas sejam substituídas por novas abordagens didáticas. Isso não significa deixar de ensinar gramática, mas fazê-lo de modo que a descrição gramatical deixe de ter um fim em si mesma, passando a constituir um meio para o desenvolvimento da competência comunicativa do aluno (OLIVEIRA, 2017). Isso dá espaço a um ensino produtivo de gramática, o qual é caracterizado pelo desenvolvimento do que Vygotsky (2002) chama de "funções cognitivas superiores", de modo que, mediado pelo professor, o aluno aprenda a refletir, analisar, sintetizar, definir, classificar, comparar, exemplificar, justificar, resumir, comentar etc. os fatos da língua (SILVA, 2017). Essa abordagem de ensino gramatical desenvolve no aluno "consciência e domínio das possibilidades de uso dos recursos linguísticos em função de sua significação e funções" (TRAVAGLIA, 2010, p. 10).

O Quadro 2, a seguir, apresenta uma relação das principais diferenças entre um ensino de gramática descontextualizado e a perspectiva da PAL:

Quadro 2 - Ensino de gramática descontextualizado x Prática de Análise Linguística

\begin{tabular}{|c|c|}
\hline \multicolumn{2}{|l|}{ Ensino de gramática } \\
\hline Objeto de ensino & Advérbios, locuções adverbiais e orações adverbiais \\
\hline Estratégia mais usada & $\begin{array}{l}\text { - Exposição de frases e períodos (ora inventados, ora retirados dos textos } \\
\text { de leitura) para identificação e classificação dos termos; } \\
\text { - Uso das explicações das gramáticas como texto didático de base para a } \\
\text { abordagem do assunto. }\end{array}$ \\
\hline Habilidade esperada & $\begin{array}{l}\text { - Identificar e classificar os termos em orações e períodos; } \\
\text { - Transformar advérbios em locuções adverbiais; } \\
\text { - Fazer a correspondência, em exercícios escolares, entre locuções } \\
\text { adverbiais e advérbios, resultando, algumas vezes, em construções que } \\
\text { não se equivalem pragmaticamente (por ex.: de forma feliz, diferente de } \\
\text { felizmente; de forma real, diferente de realmente.) }\end{array}$ \\
\hline \multicolumn{2}{|l|}{ Análise linguística } \\
\hline Objeto de ensino & Expressões adverbiais, indicadoras de circunstâncias \\
\hline Sugestão de estratégia & $\begin{array}{l}\text { - Leitura e comparação de gêneros diversos; } \\
\text { - Observação de casos particulares para se chegar a condições mais gerais; } \\
\text { - Consulta a manuais, gramáticas e dicionários para ampliar as discussões e } \\
\text { o próprio repertório de expressões etc. }\end{array}$ \\
\hline
\end{tabular}




\begin{tabular}{|l|l|}
\hline Habilidade esperada & Perceber que: \\
& - As circunstâncias podem ser sinalizadoras (por meio dos adjuntos \\
adverbiais e de outros recursos), constituindo-se expectativas de leitura e \\
matizes de sentido relevantes para a compreensão global (ex.: o uso de $\mathrm{Na}$ \\
verdade, indicando a posição do locutor); \\
- Em diferentes gêneros, há usos específicos desses recursos para atender \\
a propósitos distintos (ex.: notícia e fábula).
\end{tabular}

Fonte: Adaptado de Mendonça (2006, p. 210-211).

Como pode ser visto no Quadro 2, a perspectiva de PAL dialoga com a concepção sociocultural de ensino, visto que articula um ensino de gramática pautado na reflexão sobre o uso e funcionamento da linguagem em contextos discursivos situados.

Em relação ao uso da linguagem, podemos realizar três tipos de atividades linguísticas, as quais representam três níveis distintos de reflexão sobre a língua: atividades linguísticas, epilinguísticas e metalinguísticas (BEZERRA; REINALDO, 2013). As atividades linguísticas são aquelas que possibilitam o uso efetivo da língua em situações comunicativas e permitem a progressão do tema em pauta. Essas atividades devem também ser prestigiadas na escola, principalmente porque possibilitam que o aluno amplie os recursos expressivos da fala e da escrita. As atividades epilinguísticas resultam de uma reflexão que toma os próprios recursos expressivos como objeto, fazendo com que os usuários suspendam o tema em pauta para refletir sobre a língua. Atividades dessa natureza possibilitam que o usuário compare expressões, possa substituí-las por outras, transforme-as etc. Por isso, essas atividades devem ter seu espaço garantido em sala de aula, uma vez que promovem o que se espera da aula de língua portuguesa: refletir sobre os usos concretos da língua. Além disso, é aqui que se abre o espaço para o processo de sistematização, e por isso surge o terceiro tipo de atividades, as metalinguísticas, por meio das quais o usuário constrói uma metalinguagem sistemática, um quadro geral que permite descrever a natureza dos processos da língua.

O que se espera é que o ensino de língua aborde de maneira equilibrada esses três tipos de atividades, mas é comum que seja priorizado apenas o terceiro grupo em detrimento dos outros dois (BEZERRA; REINALDO, 2013). Considerando-se a perspectiva de andaime, é imprescindível que esse equilíbrio ocorra e que a escola proporcione um espaço de reflexão sobre o uso (atividades epilinguísticas), levando o aluno a construir reflexões mais gerais sobre a natureza da língua (atividades metalinguísticas) de maneira mais autônoma e crítico-reflexiva. Esse percurso é imprescindível, também, para que o aluno "amadureça seus conceitos", internalizando conceitos verdadeiros no lugar daqueles que, muitas vezes, parecem verdadeiros, pois o aluno os emprega adequadamente, mas quando precisa explicar seu uso, experimenta dificuldades (FRIEDRICH, 2012).

Dessa forma, a PAL pode ser tomada como ponto de partida, já que possibilita, 
confrontada, inicialmente, com as habilidades do corpus, elucidar em que medida o documento normativo, por sua vez, prestigia a formação crítico-reflexiva, ou, como o próprio documento declara, a "superação da fragmentação radicalmente disciplinar do conhecimento, o estímulo a sua aplicação na vida real" (BNCC, 2018, p. 15).

\section{Percurso metodológico: universo, corpus e procedimentos analíticos}

O universo de análise compreende a BNCC, em específico as habilidades de Análise Linguística/Semiótica dos anos finais (6 a 9o anos) da etapa Ensino Fundamental. Optamos por analisar apenas o eixo da Análise Linguística/Semiótica, principalmente porque tal prática se desenvolve transversalmente aos eixos de Leitura e Produção de Textos, ou seja, compreende um conjunto de aprendizagens fundamentais para o desenvolvimento das demais práticas de linguagem.

Desse eixo, selecionamos as habilidades de 6으, 7으, 8으 e 9음 anos (de forma individual, embora o documento ainda contemple habilidades para os blocos de anos 6ㅇ e 70 anos, 8ㅇ e 9 anos e 6ㅇ a 9ㅇaㅇ), e o campo de atuação intitulado Todos os campos. Esse recorte se deve ao fato de que Todos os campos de atuação está presente, no documento, apenas no eixo de Análise Linguística/Semiótica, e não ocorre nos eixos de Leitura/Escuta, Produção de Textos e Oralidade. O corpus de análise, dessa forma, compreende 44 habilidades do eixo Análise Linguística/Semiótica ${ }^{5}$. Dessas 44 habilidades, 10 pertencentes ao 6으 ano, 12 ao 7으 ano, 13 ao 8o ano e 9 ao 9o ano, conforme Quadro 3:

Quadro 3 - corpus de análise

\begin{tabular}{|c|c|c|c|c|}
\hline Ano escolar & 6o ano & 70 ano & 8o ano & 9o ano \\
\hline $\begin{array}{l}\text { Códigos das } \\
\text { habilidades }\end{array}$ & $\begin{array}{l}\text { \#EF06LP03 } \\
\text { \#EF06LP04 } \\
\text { \#EF06LP05 } \\
\text { \#EF06LP06 } \\
\text { \#EF06LP07 } \\
\text { \#EF06LP08 } \\
\text { \#EF06LP09 } \\
\text { \#EF06LP10 } \\
\text { \#EF06LP11 } \\
\text { \#EF06LP12 }\end{array}$ & $\begin{array}{l}\text { \#EF07LP03 } \\
\text { \#EF07LP04 } \\
\text { \#EF07LP05 } \\
\text { \#EF07LP06 } \\
\text { \#EF07LP07 } \\
\text { \#EF07LP08 } \\
\text { \#EF07LP09 } \\
\text { \#EF07LP10 } \\
\text { \#EF07LP11 } \\
\text { \#EF07LP12 } \\
\text { \#EF07LP13 } \\
\text { \#EF07LP14 }\end{array}$ & $\begin{array}{l}\text { \#EF08LP04 } \\
\text { \#EF08LP05 } \\
\text { \#EF08LP06 } \\
\text { \#EF08LP07 } \\
\text { \#EF08LP08 } \\
\text { \#EF08LP09 } \\
\text { \#EF08LP10 } \\
\text { \#EF08LP11 } \\
\text { \#EF08LP12 } \\
\text { \#EF08LP13 } \\
\text { \#EF08LP14 } \\
\text { \#EF08LP15 } \\
\text { \#EF08LP16 }\end{array}$ & $\begin{array}{l}\text { \#EF09LP04 } \\
\text { \#EF09LP05 } \\
\text { \#EF09LP06 } \\
\text { \#EF09LP07 } \\
\text { \#EF09LP08 } \\
\text { \#EF09LP09 } \\
\text { \#EF09LP10 } \\
\text { \#EF09LP11 } \\
\text { \#EF09LP12 }\end{array}$ \\
\hline
\end{tabular}

Fonte: Elaborado pelos autores (2020).

\footnotetext{
${ }^{5}$ O corpus está disponível em: http://basenacionalcomum.mec.gov.br/. Acesso em 30 mar. 2019.
} 
Após a delimitação do corpus, passamos para as etapas de análise contextual e textual. $\mathrm{Na}$ análise contextual, investigamos as etapas do processo de produção do documento, sua organização geral e a organização específica do componente curricular Língua Portuguesa. Na análise textual, investigamos os dados/habilidades do corpus. Para conduzir a análise, consideramos, primeiramente, os verbos que compõem as habilidades selecionadas. Torna-se pertinente enfatizar os verbos porque eles são o núcleo experiencial da estrutura típica das orações analisadas e permitem a compreensão da natureza e, em última instância, do nível de complexidade dos verbos (BLOOM et al., 1983) contemplados pelas habilidades de Análise Linguística/Semiótica preconizadas pela BNCC. Os verbos, portanto, tornaram-se os "recursos ricos [...] significativos no contexto que buscamos analisar" (BARTON, 2004, p. 75), já que nosso objetivo é compreender, em um sentido mais amplo, se as habilidades selecionadas estão alinhadas à perspectiva sociocultural de ensino e aprendizagem, o que, evidentemente, extrapola as fronteiras textuais.

A noção de recursos ricos em significação, adotada como base para nosso percurso metodológico, consiste em buscar, em um texto - ou conjunto de textos - características particulares que apontam para a relação entre um texto e seu contexto (BARTON, 2004). Essas características particulares adquirem relevância a partir do momento em que assumem, mediante uma análise holística e inicialmente intuitiva, um padrão de ocorrência. Segundo a autora, a recorrência, em textos, de determinados elementos linguísticos (itens lexicais) ou padrões linguísticos têm o poder de elucidar informações significativas dos contextos que moldam esses textos. Portanto, recursos ricos em significação representam quaisquer padrões que se identifiquem em um texto - ou em textos - e que podem auxiliar na compreensão dos contextos mais amplos em que esses textos se inserem. No caso desta análise, a estrutura das habilidades (Figura 2), dada sua natureza recorrente e padronizada, tornou-se o "recurso rico em significação".

Em seguida, analisamos o verbo de cada oração à luz do quadro de Processos cognitivos por nível de complexidade (Figura 3), elaborado com base na taxonomia de objetivos educacionais de Bloom et al. (1983), alocando cada verbo em um dos seis níveis que o quadro contempla. Além disso, simultaneamente, analisamos as habilidades, em seu aspecto semântico, procurando compreender se o que preconiza a BNCC enquanto habilidades de Análise Linguística/Semiótica está em consonância com uma a Prática de Análise Linguística.

Por último, a fim de conceber maior especificidade na análise dos verbos e verificar se as habilidades analisadas contemplam a perspectiva de "andaimes de aprendizagem", consideramos também cada habilidade em relação ao tipo de atividade linguística (GERALDI, 1997; BEZERRA; REINALDO, 2013) que é enfatizado: se propriamente linguística, epilinguística ou metalinguística. 


\section{Análise e apresentação dos resultados}

A Base Nacional Comum Curricular, documento oficial de caráter normativo da Educação Básica (compreendendo as etapas Educação Infantil, Ensino Fundamental e Ensino Médio), apresenta um conjunto de referenciais a serem utilizados na elaboração e adequação de currículos de escolas de todo o país, na produção de livros e materiais didáticos, na formação inicial e continuada de professores e, principalmente, na orientação de práticas docentes.

O processo de produção do documento teve a duração de quatro anos e passou por diversas etapas ao longo de seis diferentes ministros da Educação. As principais etapas desse longo processo estão apresentadas no Quadro 4.

Quadro 4 - Etapas do processo de produção da BNCC

\begin{tabular}{|c|l|}
\hline Mês/ano & \multicolumn{1}{|c|}{ Etapa } \\
\hline junho de 2014 & $\begin{array}{l}\text { Regulamentação do Plano Nacional de Educação (PNE), que, de vinte metas } \\
\text { estabelecidas para a melhoria da qualidade da Educação Básica, quatro } \\
\text { relacionam-se à necessidade de elaboração e implementação da BNCC. }\end{array}$ \\
\hline setembro de 2015 & $\begin{array}{l}\text { A primeira versão do documento é disponibilizada para posterior } \\
\text { mobilização de escolas e discussão da versão preliminar. }\end{array}$ \\
\hline maio de 2016 & $\begin{array}{l}\text { A segunda versão é disponibilizada e debatida, em diversos seminários } \\
\text { estaduais, por professores, gestores e especialistas em educação. }\end{array}$ \\
\hline agosto de 2016 & $\begin{array}{l}\text { Começa a ser redigida a terceira versão da BNCC em um processo } \\
\text { colaborativo com base na segunda versão. }\end{array}$ \\
\hline dezembro de 2017 de 2017 & $\begin{array}{l}\text { Entrega da versão final do documento (etapas Educação Infantil e Ensino } \\
\text { Fundamental) ao Conselho Nacional de Educação (CNE) para aprovação. }\end{array}$ \\
\hline dezembro de 2018 & $\begin{array}{l}\text { Homologação das etapas Educação Infantil e Ensino Fundamental pelo } \\
\text { Ministro da Educação, Mendonça Filho. }\end{array}$ \\
\hline $\begin{array}{l}\text { Homologação da etapa Ensino Médio pelo Ministro da Educação, Rossieli } \\
\text { Soares. }\end{array}$ \\
\hline
\end{tabular}

Fonte: Elaborado com base no Histórico da $\mathrm{BNCC}^{6}$ (2020).

A proposta de elaboração do documento segue, sobretudo, "princípios éticos, políticos e estéticos que visam à formação humana integral e à construção de uma sociedade justa, democrática e inclusiva" (BRASIL, 2018, p. 7), a fim de proporcionar aos estudantes de todo o país, com tantas diferenças culturais, econômicas e sociais, as mesmas oportunidades

\footnotetext{
${ }^{6}$ Histórico disponível em: http://basenacionalcomum.mec.gov.br/historico. Acesso em 30 mar. 2019.
} 
no que diz respeito à educação. Entretanto, ao estabelecer um conjunto de referenciais que representariam um padrão comum a todo o território nacional, no que diz respeito aos conteúdos básicos a serem abordados pela escola, a BNCC age, em grande medida, contraditoriamente, uma vez que o que é determinado pelo documento pode não se ajustar a esta ou aquela necessidade, dependendo de cada contexto cultural em que se dá o processo de ensino. Nessa perspectiva, há de se considerar que o "conjunto de aprendizagens essenciais aos estudantes brasileiros" (BRASIL, 2018, p. 5) é, na prática, um currículo mínimo e tudo que consta no documento é obrigatório e não pode deixar de ser incluído nos currículos escolares (TílIO, 2019).

A BNCC é organizada com foco em dez competências gerais a serem desenvolvidas ao longo de todas as etapas da Educação Básica. Dialogando com as competências gerais, em cada área do conhecimento e nos diferentes componentes curriculares, são apresentadas competências específicas. De acordo com o texto, as competências podem ser definidas como "a mobilização de conhecimentos (conceitos e procedimentos), habilidades (práticas cognitivas e socioemocionais), atitudes e valores para resolver demandas da vida cotidiana, do pleno exercício da cidadania e do mundo do trabalho" (BRASIL, 2018, p. 8). Além disso, para dar conta dessas competências, em cada componente curricular são apresentadas diferentes habilidades.

No componente curricular Língua Portuguesa (anos finais do Ensino Fundamental) as habilidades são organizadas por anos e blocos de anos, campos de atuação (artísticoliterário, práticas de estudo e pesquisa, jornalístico-midiático, atuação na vida pública), práticas de linguagem (eixos de ensino) e diferentes objetos de conhecimento. Essa organização pode ser observada no Quadro 5 a seguir, em que estão apresentadas as habilidades 06 (do 8a ano) e 05 (do 9o ano) do corpus selecionado:

Quadro 5 - Organização das habilidades de Língua Portuguesa

\begin{tabular}{|c|c|c|c|}
\hline \multirow{2}{*}{$\begin{array}{l}\text { PRÁTICAS DE } \\
\text { LINGUAGEM }\end{array}$} & \multirow{2}{*}{$\begin{array}{c}\text { OBJETOS DE } \\
\text { CONHECIMENTO }\end{array}$} & \multicolumn{2}{|c|}{ HABILIDADES } \\
\hline & & 8 ANO & 9 ANO \\
\hline \multicolumn{4}{|c|}{ TODOS OS CAMPOS DE ATUAÇÃO } \\
\hline $\begin{array}{c}\text { Análise linguística/ } \\
\text { semiótica }\end{array}$ & Morfossintaxe & $\begin{array}{l}\text { (EF08LP06) Identificar, em } \\
\text { textos lidos ou de } \\
\text { produção própria, os } \\
\text { termos constitutivos da } \\
\text { oração (sujeito e seus } \\
\text { modificadores, verbo e } \\
\text { seus complementos e } \\
\text { modificadores). }\end{array}$ & $\begin{array}{l}\text { (EF09LP05) Identificar, em } \\
\text { textos lidos e em } \\
\text { produções próprias, } \\
\text { orações com a estrutura } \\
\text { sujeito-verbo de ligação- } \\
\text { predicativo. }\end{array}$ \\
\hline
\end{tabular}

Fonte: Elaborada com base em Brasil (2018, p. 188-189). 
É importante destacar que a organização das práticas de linguagem por campos de atuação, segundo o documento, "aponta para a importância da contextualização do conhecimento escolar, para a ideia de que essas práticas derivam de situações da vida social e, ao mesmo tempo, precisam ser situadas em contextos significativos para os estudantes" (BNCC, 2018, p. 84). No entanto, as 44 habilidades selecionadas para esta análise pertencem ao escopo Todos os campos de atuação, revelando certa descontextualização dessas atividades de Análise Linguística/Semiótica e sugerindo que poderiam ser contempladas em quaisquer campos de atuação e gêneros textuais. Isso corrobora, em grande medida, uma perspectiva de ensino e de aprendizagem que não contempla a Prática de Análise Linguística e, por isso, afasta-se da perspectiva sociocultural que busca situar os objetos de ensino com vistas a torná-los significativos.

O componente curricular Língua Portuguesa, assim como os demais componentes curriculares da BNCC, apresenta habilidades que "expressam as aprendizagens essenciais que devem ser asseguradas aos alunos nos diferentes contextos escolares." (BRASIL, 2018, p. 29). Desse modo, elas são descritas de acordo com uma estrutura típica, conforme a Figura 2:

Figura 2 - Estrutura típica das habilidades na BNCC

Empregar as regras básicas de concordância nominal e verbal em situações comunicativas e na produção de textos.
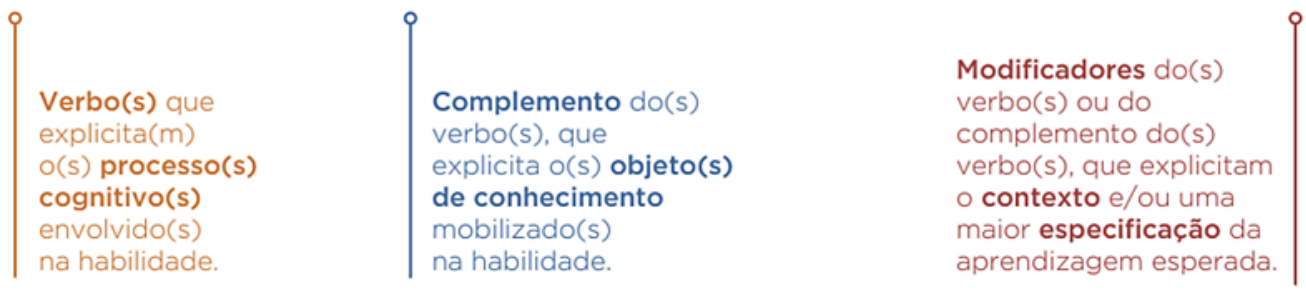

Fonte: Adaptado do documento (2018, p. 29) com habilidade \#EF07LP06 do corpus.

Partindo dessa estrutura, de 44 habilidades selecionadas, foram analisadas 57 orações (visto que algumas habilidades compreendem mais de um verbo). As orações, conforme Figura 2, são constituídas por verbo (que indica o processo cognitivo), complemento (que indica o(s) objeto(s) de conhecimento) e modificador (quando há necessidade de explicitar o contexto e/ou maior especificação da aprendizagem esperada). Importante destacar que essa estrutura não se mantém em todo o corpus, por exemplo, os modificadores, que "devem ser entendidos como a explicitação da situação ou condição em que a habilidade deve ser desenvolvida, considerando a faixa etária dos alunos", (BRASIL, 2018 , p. 30) não ocorrem em muitas orações. Essa exclusão sugere a proposição de habilidades descontextualizadas de práticas situadas de uso da linguagem.

Com base na taxonomia de objetivos educacionais proposta por Bloom et al. (1983), 
elaboramos o quadro de processos cognitivos por níveis de complexidade (Figura 3) contemplando os verbos das orações analisadas. Os níveis de complexidade seguem uma ordem que não deve ser tomada como regra, mas como possibilidade que pode auxiliar o aluno na construção de andaimes, ou seja, uma proposta que envolve o desenvolvimento de habilidades orientadas por verbos que indicam processos cognitivos da ordem do conhecer (1), compreender (2), aplicar (3), analisar (4), sintetizar (5) e, por fim, avaliar (6).

Figura 3 - Processos cognitivos por nível de complexidade

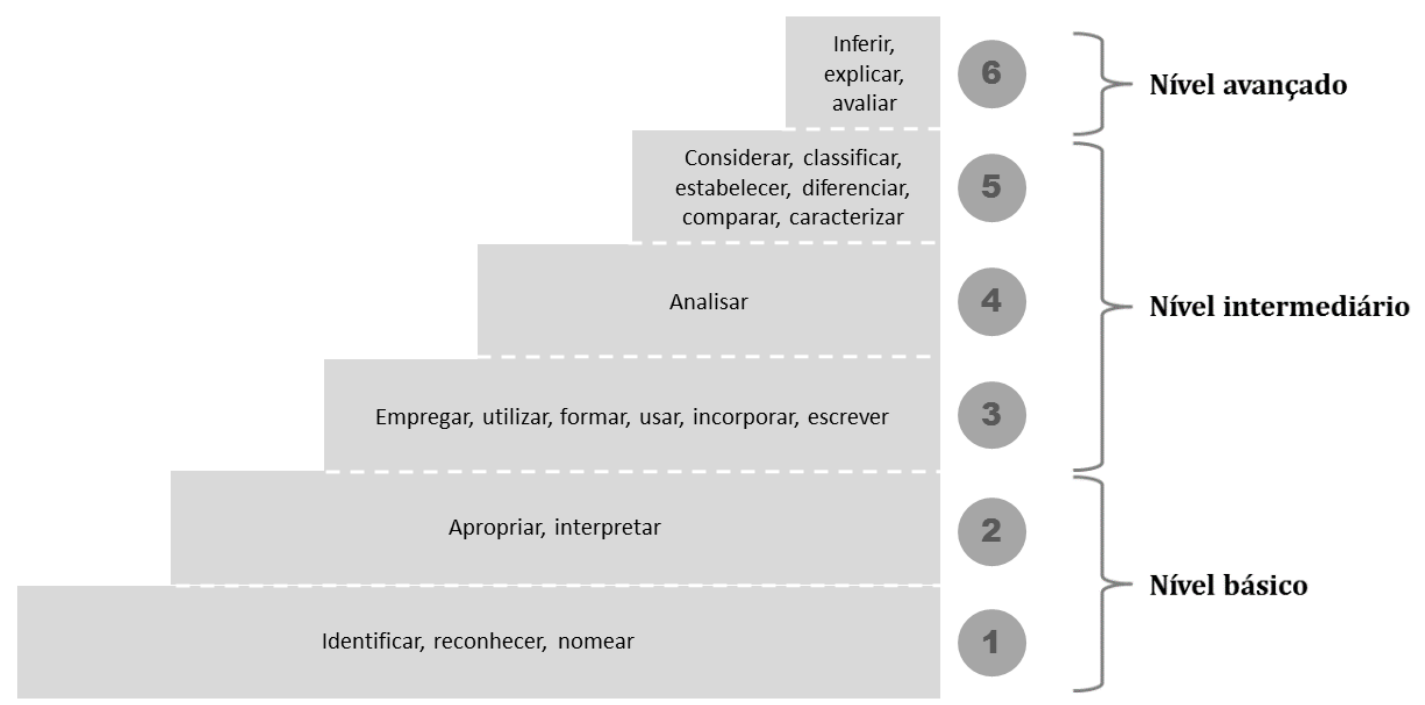

Fonte: Elaborada pelos autores, com base em Bloom et al. (1983), considerando o corpus analisado (2020).

A partir da disposição dos verbos em cada nível de complexidade correspondente, organizamos em uma tabela o número de verbos de cada nível de complexidade contemplados em cada ano escolar. De acordo com a Tabela 1, o 60 ano apresenta um total de 12 verbos, o 70 ano apresenta 13, o 8 ano apresenta 21 e o 9o ano apresenta 11 . Desse modo, consideramos um total de 57 orações, focalizando, principalmente, os verbos que orientam o desenvolvimento das habilidades.

Tabela 1 - Relação nível de complexidade $x$ ano escolar ${ }^{7}$

\begin{tabular}{|c|c|c|c|c|c|}
\hline \multirow{2}{*}{$\begin{array}{c}\text { Níveis de } \\
\text { complexidade }\end{array}$} & \multicolumn{4}{|c|}{ Anos escolares } & \multirow{2}{*}{$\begin{array}{l}\text { Total de verbos } \\
\text { por nível de } \\
\text { complexidade }\end{array}$} \\
\hline & 60 ano & 70 ano & 8o ano & 9o ano & \\
\hline 6 - avaliar & - & - & 2 (50\%) & 2 (50\%) & 4 \\
\hline
\end{tabular}

\footnotetext{
${ }^{7}$ O percentual apresentado ao lado do número total de verbos por ano escolar é calculado considerando-se o número de verbos em relação ao número total de verbos por nível de complexidade, e não do número total de verbos (57).
} 


\begin{tabular}{|c|c|c|c|c|c|}
\hline 5 - sintetizar & $2(20 \%)$ & $1(10 \%)$ & $3(30 \%)$ & $4(40 \%)$ & 10 \\
\hline 4 - analisar & $2(66,6 \%)$ & - & $1(33,3 \%)$ & - & 3 \\
\hline 3 - aplicar & $3(25 \%)$ & $3(25 \%)$ & $5(41,6 \%)$ & $1(08 \%)$ & 12 \\
\hline 2 - compreender & - & - & $5(100 \%)$ & - & 5 \\
\hline 1 - conhecer & $5(21,7 \%)$ & $9(39,1 \%)$ & $5(21,7 \%)$ & $4(17,3 \%)$ & 23 \\
\hline $\begin{array}{l}\text { Total de verbos } \\
\text { por ano escolar }\end{array}$ & $12(21 \%)$ & $13(22,8 \%)$ & $21(36,8 \%)$ & $11(19,2 \%)$ & 57 \\
\hline
\end{tabular}

Fonte: Elaborada pelos autores (2020).

Como pode ser observado na Tabela 1, somente os níveis da ordem do conhecer (1), do aplicar (3) e do sintetizar (5), são contemplados em todos os anos escolares, embora não haja uma progressão em termos de processos cognitivos, considerando o emprego de verbos entre os anos escolares. No 6음 ano, especificamente, as habilidades não contemplam o nível da ordem do compreender e não atingem o nível de avaliação. No 70 ano, destaca-se o número considerável de verbos da ordem do conhecer (69\% do total de verbos envolvidos nesse ano escolar). Diferentemente dos anos anteriores, no $8^{\circ}$, todos os níveis são contemplados e é visível certa progressão e equilíbrio em relação aos verbos e seus respectivos níveis de complexidade. Por fim, no 9o ano, os verbos privilegiam os níveis intermediário e avançado da complexidade cognitiva, mas os níveis da ordem do compreender e do analisar, entendidos como fundamentais para que a aprendizagem seja assegurada e se efetive a construção de andaimes, não são considerados. É importante destacar que o processo cognitivo refletir, imprescindível para o desenvolvimento de habilidades do eixo de Análise Linguística/Semiótica, não é empregado em nenhuma oração. Constata-se, portanto, certa fragilidade na proposição das habilidades, visto que elas não garantem a progressão de níveis de complexidade esperada em cada ano escolar.

A partir da análise das orações que contemplam as habilidades do corpus, ou seja, de um olhar não apenas para os verbos que indicam os processos cognitivos envolvidos nas habilidades, mas também para os complementos e eventuais modificadores, buscamos compreender em que medida as habilidades contemplam um ensino de Prática de Análise Linguística no corpus. Esse enfoque, considerando a oração em sua totalidade, permite compreender de maneira mais ampla a presença - ou não - de elementos fundamentais para a perspectiva sociocultural, o que a análise dos verbos, por si só, não possibilita.

Embora o documento destaque que a fragmentação dos eixos de ensino (leitura, produção textual e análise linguística/semiótica) seja realizada para fins de organização curricular (Brasil, 2018, p. 82), apenas algumas habilidades do corpus sugerem uma possível integração entre as práticas de linguagem, ao apresentar, na posição de modificador, o contexto em que determinado conteúdo deve ser desenvolvido, como é o caso da habilidade (EF06LP07): “Identificar, em textos, períodos compostos por orações separadas por vírgula 
sem a utilização de conectivos, nomeando-os como períodos compostos por coordenação.". No entanto, com relação a isso, evidencia-se uma lacuna do documento ao indicar o texto (ou modificadores como: "em textos lidos ou sequência textual", "em textos lidos ou de produção própria" etc.) como contexto da aprendizagem e não como objeto de estudo, divergindo do que é assegurado pelo documento (2018, p. 67) nos pressupostos pedagógicos que antecedem as habilidades propriamente ditas:

Assume-se aqui a perspectiva enunciativo-discursiva de linguagem. [...] Tal proposta assume a centralidade do texto como unidade de trabalho e as perspectivas enunciativo-discursivas na abordagem, de forma a sempre relacionar os textos a seus contextos de produção e o desenvolvimento de habilidades ao uso significativo da linguagem em atividades de leitura, escuta e produção de textos em várias mídias e semioses. (BRASIL, 2018, p. 67)

Em habilidades como "Identificar, em textos lidos ou de produção própria, agrupamento de orações em períodos, diferenciando coordenação de subordinação" (EF08LP11), o objeto de estudo diz respeito à língua e não ao texto, que deveria ser tomado como ponto de partida para o estudo de determinados fenômenos linguísticos. Ou seja, as habilidades não privilegiam o uso para abordar conteúdos linguísticos (estruturais, textuais, discursivos, normativos) que têm relação com as especificidades de cada gênero, seu propósito sociocomunicativo e suas condições de produção. Desse modo, dependerá do professor a integração entre os eixos e a abordagem dos conteúdos indicados pelo documento em gêneros textuais específicos, tomando a Prática de Análise Linguística como ferramenta para o desenvolvimento das demais práticas de linguagem e não o inverso. Além disso, o fato de existir um "Campo de atuação: todos os campos" parece reforçar a ideia de que o objeto de ensino contemplado pelas habilidades, pelo menos nesse campo, pode ser tomado fora de um contexto situado, relativamente descontextualizado de seu uso efetivo, o que vai de encontro à perspectiva sociocultural de ensino e aprendizagem.

As habilidades analisadas foram também classificadas de acordo com a natureza das atividades da língua que elas prestigiam, conforme representado na Tabela 2.

Tabela 2 - Relação número de habilidades $x$ ano escolar x natureza da atividade linguística8

\begin{tabular}{|c|c|c|c|c|c|}
\hline Atividade Linguística & 6o ano & 70 ano & 8 ano & 9o ano & Total de atividades \\
\hline Linguística & $3(30 \%)$ & $3(25 \%)$ & $3(23 \%)$ & $1(11 \%)$ & $10(22,7 \%)$ \\
\hline Epilinguística & $3(30 \%)$ & $4(33,3 \%)$ & $7(53,8 \%)$ & $7(77,7 \%)$ & $21(47,7 \%)$ \\
\hline Metalinguística & $4(40 \%)$ & $5(41,6 \%)$ & $3(23 \%)$ & $1(11 \%)$ & $13(29,5 \%)$ \\
\hline Total de atividades & $10(22,7 \%)$ & $12(27,2 \%)$ & $13(29,5 \%)$ & $9(20,4 \%)$ & 44 \\
\hline
\end{tabular}

Fonte: Elaborada pelos autores (2020).

\footnotetext{
${ }^{8}$ O percentual é calculado em relação ao número total de habilidades para cada ano escolar, e não ao número total de habilidades (44).
} 
Do total de 44 habilidades, 10 delas $(22,7 \%)$ enfatizam atividades de natureza linguística, 21 (47,7\%) priorizam atividades epilinguísticas e 13 (29,5\%), atividades metalinguísticas. Considera-se positivo que mais da metade das habilidades prestigiem atividades de reflexão sobre a língua (epilinguísticas), e apenas um terço, aproximadamente $(29,5 \%)$, prestigie atividades metalinguísticas, o que confronta o cenário que a escola costuma construir em relação a atividades dessa natureza, quando elas são maioria no ensino da língua, conforme já se afirmou. O significativo número de habilidades que prestigiam atividades de reflexão sobre a língua $(47,7 \%)$, entretanto, não pode ser tomado como indicativo de que essa reflexão realmente seja priorizada de maneira satisfatória. Uma habilidade predominantemente metalinguística como, (EF08LP12) "Identificar, em textos lidos, orações subordinadas com conjunções de uso frequente, incorporando-as às suas próprias produções", não garante que o aluno que identificar as conjunções e empregá-las, depois, em seus textos de maneira adequada, terá realmente compreendido os efeitos de sentido de seu uso, permanecendo no nível do que Vygostsky chama de pseudoconceito.

Outra consideração importante reside no fato de que, embora 22 habilidades analisadas prestigiem atividades predominantemente epilinguísticas, no 60 ano, que possui um total de 10 habilidades, atividades dessa natureza representam o mesmo número das metalinguísticas (30\%), com 3 habilidades contemplando cada uma delas. Algo semelhante ocorre com o 70 ano, em que, das 12 habilidades, 5 (41,6\%) são de natureza metalinguística, e apenas $4(33,3 \%)$ de natureza epilinguística. Isso merece reflexão, uma vez que, na escala de anos analisados, 60 e 7을 anos correspondem a níveis de escolaridade que constroem os pilares para a conclusão do Ensino Fundamental, diferentemente dos 8 ㅇ e 9ㅇaㅁ anos, os quais representam momentos da formação escolar caracterizados por um maior nível de complexidade de conceitos - o que abriria, em tese, espaço a um maior número de atividades metalinguísticas - mas apresentam, respectivamente, de acordo com esta análise, 23 e $11 \%$ de habilidades que prestigiam atividades metalinguísticas.

Ou seja, em anos escolares cujo nível de abstração dos conceitos trabalhados tende a ser maior (mais científicos do que cotidianos), o percentual de atividades metalinguísticas é consideravelmente menor do que em níveis anteriores, em que esse percentual é igual ou maior do que aquele de atividades de reflexão sobre a língua. Ou seja, quanto mais o aluno teria condições de abordar e compreender conceitos de segunda ordem, menos espaço as habilidades dão a atividades nesse sentido. Inversamente, quanto mais próximo dos conceitos cotidianos o aluno se encontra (60 e 7ㅇs anos, em comparação a 8o e 9으), mais é esperado que ele compreenda conceitos de segunda ordem (metalinguísticos). A organização das habilidades analisadas não contribui para a construção andaimes essenciais à reflexão sobre o uso da língua.

Ao se comprometer com o desenvolvimento crítico-reflexivo do aluno frente às mais diversas práticas sociais permeadas pela linguagem, o documento sinaliza para a adoção de práticas pedagógicas inseridas em uma perspectiva sociocultural, caracterizada pela reflexão 
mediada pela linguagem, pela adoção de andaimes de aprendizagem, pelo desenvolvimento da autonomia (por meio da construção de conceitos verdadeiros) e, consequentemente, por uma abordagem de PAL. Todavia, de acordo com a análise (embora ela represente apenas um recorte dentre todas as habilidades de Análise Linguística/Semiótica, e não contemple os blocos de anos), foi possível constatar que as habilidades não prestigiam uma perspectiva sociocultural de ensino e aprendizagem da forma como deveriam/poderiam.

Nessa breve análise, foi verificada certa dicotomia em relação ao que deve ser feito "para" o aluno e "como" isso deve ser feito: enquanto uma perspectiva sociocultural assume que, para que o aluno desenvolva a autonomia linguística, é imprescindível construir andaimes de aprendizagem; a BNCC, assumindo esse mesmo objetivo, minimiza a apresentação de uma estrutura de habilidades para o ensino de Língua Portuguesa que possibilite essa construção, elegendo uma estrutura de habilidades que adota a língua como objeto de estudo, desconsiderando o texto ou gêneros textuais específicos. Nesse sentido, o documento pode conduzir a uma abordagem em que o texto passa a ser mero pretexto para as atividades em sala de aula quando considerado o eixo da Análise linguística/semiótica em relação a Todos os Campos.

\section{Considerações finais}

Nossa análise, embora considere apenas o recorte das habilidades do eixo de Análise Linguística/Semiótica do escopo Todos os campos de atuação dos 6으, 7으, 8ㅇ e 9o anos do Ensino Fundamental, permite concluir que, embora assuma um posicionamento que prestigia a formação de alunos crítico-reflexivos, autônomos frente aos mais diversos contextos de uso da linguagem, o que está em consonância com a perspectiva sociocultural de ensino e aprendizagem, a BNCC apresenta fragilidades quanto aos meios pelos quais esse tipo de aprendizagem pode se efetivar.

Em um contexto educacional que abrange diferentes e variadas concepções teóricas, o fato de que até mesmo os documentos normativos/institucionais relacionados aos processos de ensino e aprendizagem carregam em si marcas de divergentes posicionamentos teóricos, reflexos das diferentes condições de produção desses documentos, constituídas, por sua vez, por diferentes modos de compreensão de objetos e abordagens de ensino parece, em alguma medida, dificultar um avanço frente aos processos de ensino e aprendizagem de linguagem.

Nesse sentido, cabe aos formadores a promoção de um papel ativo do professor de Língua Portuguesa frente ao documento, lembrando sempre, em última instância, daquilo que a BNCC realmente representa: um documento normativo que determina as práticas pedagógicas, o que, entretanto, não retira do professor sua agência na recontextualização 
de conteúdos programáticos e práticas pedagógicas ao seu contexto de atuação, a fim de garantir que as competências linguísticas esperadas sejam construídas pelos seus alunos. Cabe, portanto, uma leitura crítica do documento, permeada pelo bom senso e pela criticidade teórico-metodológica, para que possamos mitigar possíveis incongruências.

\section{Referências}

BARTON, E. Linguistic discourse analysis: how the language in texts works. In: BAZERMAN, C.; PRIOR, R. (Eds.) What writing does and how it does it: An introduction to analyzing texts and textual practices. Mawhaw, NJ: Lawrence Erlbaum, 2004. p. 57-82.

BEZERRA, M. A.; REINALDO, M. A. Análise Linguística: afinal, a que se refere? São Paulo: Cortez, 2013.

BLOOM, B. et al. Taxonomia dos objetivos educacionais: domínio cognitivo. Porto Alegre: Globo, 1983.

BRASIL. Ministério da Educação. Base Nacional Comum Curricular. Brasília: MEC, 2018. Disponível em: <http://basenacionalcomum.mec.gov.br>. Acesso em 30 mar. 2019.

FARIAS, S. A.; BORTOLANZA, A. M. E. Concepção de mediação: o papel do professor e da linguagem. Revista Profissão Docente, v. 13, n. 29, p. 94-109, 2013.

FIGUEIREDO, F. J. Q. Vygotsky: a interação no ensino e aprendizagem de línguas. São Paulo: Parábola, 2019.

FRIEDRICH, J. A formação dos conceitos na criança. In: FRIEDRICH, J. Lev Vigotski - Mediação, aprendizagem e desenvolvimento. Uma leitura filosófica e epistemológica. Campinas, SP: Mercado das Letras, 2012, p. 77-98.

FRIEDRICH, J. A. O aporte específico da escola. In: FRIEDRICH, J. Lev Vigotski - Mediação, aprendizagem e desenvolvimento. Uma leitura filosófica e epistemológica. Campinas, SP: Mercado das Letras, 2012. p. 99-118.

GERALDI, J. W. O texto na sala de aula. 2. ed. Cascavel: Assoeste, 1984.

GERALDI, J. W. Portos de Passagem. São Paulo: Martins Fonte, 1997.

LINO DE ARAÚJO, D. Enunciado de atividades e tarefas escolares: modos de fazer. 1. ed. São Paulo: Parábola Editorial, 2017.

MENDONÇA, M. A. Análise linguística no ensino médio: um novo olhar, um outro objeto. In: BUNZEN, C.; MENDONÇA, M.; (Org.). Português no ensino médio e formação do professor. 2. ed. São Paulo: Parábola Editorial, 2006. p. 199-226.

OLIVEIRA, R. M. Linguística funcional centrada no uso e no ensino. In: CASSEB-GALVÃO, V.; MOURA NEVES, M. H.; (Org.). O todo da língua: teoria e prática do ensino de português. 1. ed. São Paulo: Parábola Editorial, 2017. p. 15-34. 
SILVA, L. A. Por um ensino produtivo de gramática. In: CASSEB-GALVÃO, V.; MOURA NEVES, M. H.; (Org.). O todo da língua: teoria e prática do ensino de português. 1. ed. São Paulo: Parábola Editorial, 2017. p. 77-95.

TílIO, R. A Base Nacional Comum Curricular e o contexto brasileiro - Prefácio. In: GERHARDT, A. F.; AMORIM, M. A. (Orgs.). A BNCC e o ensino de línguas e literaturas. 1. ed. Campinas, SP: Pontes Editores, 2019. p. 07-15.

TRAVAGLIA, L. C. Que análise linguística operacionalizar no ensino de Língua Portuguesa? In: TAGLIANI, D. et. al. (Org.). Anais do II Seminário Nacional sobre Linguística e Ensino de Língua Portuguesa - $O$ ensino de Língua Portuguesa no séc. XXI: desafios e possibilidades. Rio Grande, RS: FURG, 2010. Disponível em: <https://senallp.furg.br>. Acesso em: 30 mar. 2019. n.p.

VYGOTSKY, L. S. A formação social da mente. São Paulo: Martins Fontes, 1991.

Recebido em: 23/09/2019.

Aceito em: 22/03/2020. 